\title{
XVI. The classes of progressive long waves
}

\section{R.F. Gwyther M.A.}

To cite this article: R.F. Gwyther M.A. (1900) XVI. The classes of progressive long waves, Philosophical Magazine Series 5, 50:303, 213-216, DOI: 10.1080/14786440009463904

To link to this article: http://dx.doi.org/10.1080/14786440009463904

$$
\text { 册 Published online: } 21 \text { Apr } 2009 .
$$

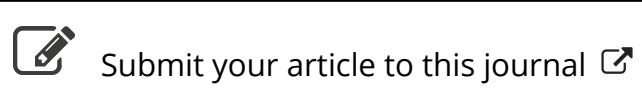

\footnotetext{
Џll Article views: 4
}

Q View related articles $\square$

Citing articles: 4 View citing articles $\square$ 
various terms in (7). If the system be such that

$$
\frac{d}{d t} \Sigma(m x y)
$$

does not continually increase, we obtain, as in the case of the virial theorem,

$$
2 \Sigma m \frac{d x}{d t} \frac{d y}{d t}=\Sigma(x \mathrm{Y}+y \mathrm{X}) . . . . .
$$

It would seem that this equation has application to the molecular theory of the viscosity of gases, analogous to that of the virial as applied to hydrostatic pressure.

XVI. The Classes of Progressive Long Waves.

$B y$ R. F. Gwrther, $M . A . *$

A DOP'IING the method employed by Lord Rayleigh in $A$ his paper "On Waves" + , write

$$
\phi+i \psi=\mathrm{E}(x+i y)
$$

where $F$ is a real function, and therefore

$$
\psi=F^{\prime} y-F^{\prime \prime \prime} \frac{y^{3}}{3 !}+\text { etc., . . . . }
$$

while the condition expressing the uniformity of pressure along the free surface, for which $\psi=-c h$, is

$$
u^{2}+v^{2}=c^{2}-2 g(y-h) \text {. . . . . }
$$

But now, instead of obtaining a differential equation approximately related to the free surface, proceed to eliminate $y$ between (1) and (2), putting $\psi=-c h$.

The convergency of these expressions in the case of long: waves is clear, and we easily obtain

$$
\begin{aligned}
& \mathrm{F}^{\prime 2}-\left(\mathrm{F}^{\prime} \mathrm{F}^{\prime \prime \prime}-\mathrm{F}^{\prime \prime 2}\right) \frac{c^{2} h^{2}}{\mathrm{~F}^{\prime 2}}+\text { etc. } \\
& =c^{2}+2 g h+2 g\left[\frac{c h}{\mathrm{~F}^{\prime}}+\frac{c^{3} h^{3} \mathrm{~F}^{\prime \prime \prime}}{3 ! \mathrm{F}^{\prime 4}}+\text { etc. }\right] .
\end{aligned}
$$

This mode of treatment has the merit of simplicity and also of allowing the constants introduced in the integration by approximate methods to be treated with a feeling of security.

Write (3) to a first approximation

$$
\begin{gathered}
\left(c^{2}+\frac{c^{3} g h}{3 \mathrm{~F}^{1 / 3}}\right) h^{2} \mathrm{~F}^{\prime \prime \prime}=\mathrm{F}^{13}-\left(c^{2}+2 g h\right) \mathrm{F}^{\prime}-2 g c h . \quad . \\
\text { * Communicated by the Author. } \\
\text { + Phil. Mag., A pril 1876. }
\end{gathered}
$$

Phil. Mag. S. 5. Vol. 50. No. 303. Aug. 1900. 
As we are seeking solutions which we have reason to think rapidly convergent, put

$$
\mathrm{F}^{\prime}=-c+f^{\prime}, \quad \text {. . . . . . }
$$

where we consider $f^{\prime}$ small compared with $c$. On this assumption (4) becomes

$$
\left(c^{2}-\frac{g h}{3}\right) h^{2} f^{\prime \prime \prime}=f^{\prime 3}-3 c f^{\prime 2}+2\left(c^{2}-g h\right) f^{\prime} . \quad .
$$

Whenever the form of the function $f^{\prime}$ is found, the form of the free surface is given by (1) or (2).

Under the conditions stipulated we may neglect $f^{\prime 3}$ compared with $3 c f^{\prime 2}$, but we can only neglect $3 c f^{2}$ compared with $2\left(c^{2}-g h\right) f^{\prime}$, when $f^{\prime}$ is small compared with $2\left(c^{2}-g h\right) / 3 c$.

Taking this to be the case, we obtain

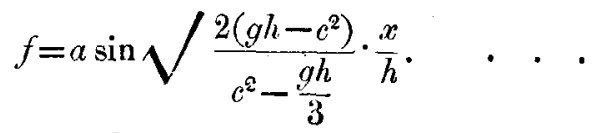

If $\lambda$ is the wave-length, we have

$$
\frac{4 \pi^{2} h^{2}}{\lambda^{2}}=\frac{2\left(g h-c^{2}\right)}{c^{2}-\frac{g h}{3}},
$$

subject to the condition that the height of the wave shall be small compared with $2\left(g h-c^{2}\right) / 3 g$.

If, for example, $h: \lambda=1: 10$, we get approximately $g h: c^{2}=9: 8$, and the height of the wave must be small compared with $2 h / 27$.

This wave can therefore be only of small amplitude, and gannot be the general case of the long wave. It has, on the usual theory, a group-velocity given by

$$
\frac{c^{3}}{g h}+\frac{\left(c^{2}-g h\right)^{2}}{2 c g h},
$$

which is slightly less than the wave-velocity.

Proceeding to the more general case, we have from (6), neglecting $f^{13}$ and integrating,

$$
\left(c^{2}-\frac{g h}{3}\right) h^{2} f^{\prime \prime 2}=-2 c f^{13}+2\left(c^{2}-g h\right) f^{\prime 2}+\text { constant ; }
$$

from this it follows that $f^{\prime}$ can be found in terms of $x$ as an elliptic function. I do not propose to consider this further bere, but it is doubtless connected with the stationary cnoidal wave of Korteweg and de Vries *.

* Phil. Mag., May 1895 , 
When $f^{\prime \prime}$ and $f^{\prime}$ vanish together, the constant in (8) is null, and the solution is completed by

$$
\begin{gathered}
f=a \tanh m x, \\
\text { where } m a=\frac{c^{2}-g h}{c}, \text { and } \\
m^{2} h^{2}=\frac{c^{2}-g h}{2\left(c^{2}-\frac{g h}{3}\right)} .
\end{gathered}
$$

Hence

$$
\frac{a^{2}}{h^{2}}=\frac{2\left(c^{2}-g h\right)\left(c^{2}-\frac{g h}{3}\right)}{c^{2}},
$$

and $c^{2}$ must be slightly greater than $g h$, whereas in the harmonic periodic wave previously considered it was necessarily slightly less.

This case represents a low solitary wave of Scott Russell, and the expression for $\phi+i \psi$, now obtained from the equations, is that assumed by Mr. MeCowan ${ }^{*}$ in his investigation of the properties of that wave.

A point of interest is that the relation $c^{2}=g h$, found by the received method as giving the velocity of a long wave, corresponds to a simple case of the cnoidal wave (8).

If we retain the term in $f^{\prime 3}$ in (6) we obtain the most general case of the elliptic function waves. In the case of the solitary wave,

where, as before,

$$
f^{\prime}=\frac{2\left(e^{2}-g h\right)}{c+\sqrt{g^{h} \cosh 2 m x}}, \quad . \quad . \quad .
$$

$$
m^{2} \iota^{2}=\frac{e^{2}-g h}{2\left(e^{2}-\frac{g h}{3}\right)} .
$$

From this the form of the free surface is readily found by (2).

The form of $f$ is also easily found to be

$$
f=h \sqrt{c^{2}-\frac{g h}{3}} \log \frac{\sqrt{c+\sqrt{g h}}+\sqrt{c-\sqrt{g h}} \tanh m x}{\sqrt{c+\sqrt{g h}-\sqrt{c-\sqrt{g h}} \tanh m x}} .
$$

The highest wave of this type can be determined by the method Sir George Stokes has taught us. We must determine the relation between the parameters $c$ and $h$ in order

* Phil. Mag., July 1891.

Q 2 
that the point for which $u^{2}+v^{2}=0$ may be at the apex of the wave, and not outside the fluid, as it will generally be.

This condition is found to lead to

$$
c \sqrt{g h} \cos 2 m y+2 g h-c^{2}=0, \quad . \quad . \quad \text {. }
$$

which can be satisfied, since $c^{2}>g h$. With this we have of course to combine

$$
y=h+\frac{e^{2}}{2 g}, \quad . \quad . \quad . \quad . \quad .
$$

and the relation between the parameters is found to be very approximately

$$
c^{2}=\frac{5 g h}{3}, \quad \text {. . . . . }
$$

giving $\frac{5 h}{6}$ for the elevation in the highest wave. These values, however, hardly lie within the limits of this paper, since in this extreme case $f^{*}: c$ will have the value 46 at the crest of the wave.

XVII. Cosmic Evolution. By Prof. A. W. Biokerton *.

$\mathrm{N}$ this paper the term galactic system will mean not only I the milky way, but also the caps of nebula at its poles. The term milky way will be used to imply the galaxy itself, The term cosmic system will be applied to aggregations of dimensions comparable to the Magellanic clouds and to our own galactic system. (In my earlier papers these masses were called universes; but Iuord Kelvin and Juord Rayleigh independently pointed out that this name might mislead, I have consequently substituted cosmic systems.) The term cosmic system of the first order applies to aggregations without definite structure, in which no general collision has accurred. In systems of the second order, a single general collision has taken place, and the symmetry is perfect. All other cosmic systems are of the third order. In these more than one general collision bas occurred, and there is too much symmetry to be of the first order, and too little symmetry to be of the second. The visible universe (the galaetic system of which our solar system is a part) is consequently a system of the third order.

The group of recently-discovered monatomic elements that have no combining power, namely, helium, neon, argan, crypton, and xenon, I call cosmic pioneers. They are practically

* Communicated by Prof. A. W. Rücker, Sec.R.S. 